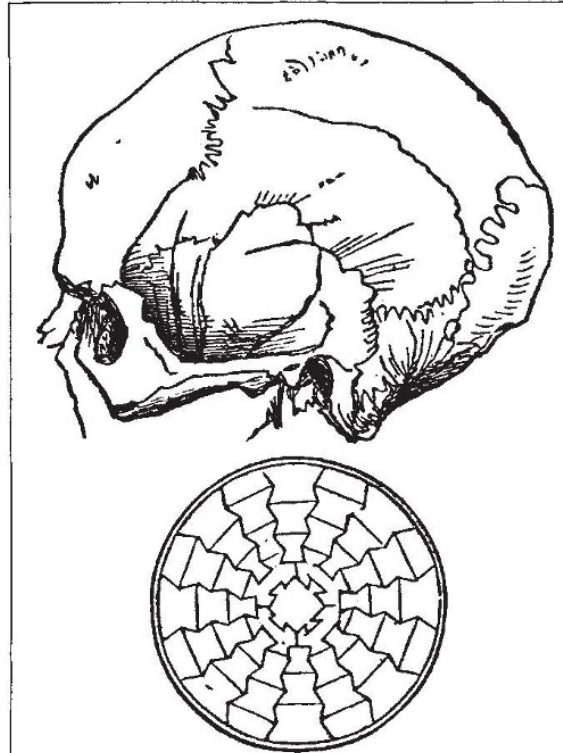

Natural principle - dovetailing in the human skull and in the stonework of the Eddystone lighthouse (seen in section). The illustration first appeared in J.G. Wood's Nature's Teachings: Human Invention Anticipated by Nature, published in 1885 .

members have to be made thick enough to prevent buckling. The lightest pillars can be made of materials of high Young's modulus and low density. Aluminium is better than steel, and magnesium would be better still were it not for the danger of fire, but wood and carbon fibre composites are better than any of the metals.

Discussions of these and similar topics fill Gordon's book, just as they filled his earlier ones. The message is the same but the presentation is glossier, with plenty of the apt colour photographs that we expect to see in the Scientific American Library. However, I found myself wondering from time to time whether Gordon's eccentric style had been curbed just a little by a wellmeaning editor - The New Science of Strong Materials was more fun.

There is quite a lot of common ground between Wainwright's and Gordon's books. Wainwright shows us the geodetic fibres in the cuticles of worms and Gordon shows us the geodetic framework of the Wellington bomber. Both authors explain how the J-shaped stress-strain curve of many biological materials helps to prevent aneurisms, swellings such as occur, for example, in the early stages of inflating a sausage-shaped balloon. Both explain the Cook-Gordon mechanism of crack stopping, though Gordon does so in more detail (which is not surprising: he discovered it). Above all, neither author is conventional and both take us from basic principles to unexpected insights. To Gordon, the Parthenon is appallingly bad engineering, and to Wainwright a worm is a sock full of meat.

R. McNeill Alexander is a Professor in the Department of Pure and Applied Biology, University of Leeds, Leeds LS2 9JT, UK.

\section{Events of no little matter}

\section{J.M. Charap}

The Great Design: Particles, Fields, and Creation. By Robert K. Adair. Oxford University Press: 1988. Pp.376. £19.50, $\$ 24.95$.

SOMEWHERE between the paranormal and psychology, most bookstores will have a shelf or two of books on physics. Most of them are likely to be pot-boilers on black holes or particle physics, and few will attract the serious attention of professional scientists - which is not to say that they do not merit such attention. I have often wondered about the people who read these books. Presumably they will include the layman with the "attentive mind" to whom Adair addresses himself; what, then, will such a layman make of a book which is overtly pedagogic, which has a scope not very different from an American university non-calculus course in 'modern physics', and even slips some of the calculus into the end-of-chapter notes?

Well, I suppose many will be put off by the equations, and will not find the diagrams with their matchstick figures of Olivia and Oliver, the two independent observers, sufficiently enchanting to persevere with the text. This is a pity, because there is a lot to be said for this treatment, which is basically a straightforward, unfussy and well-ordered account of the core concepts of relativistic particle physics.

Most particle physicists would place conservation laws and invariance in this core. If pressed, most others would agree. And Adair puts these concepts right up front. He is very good in his treatment of special relativity, and even gets in a chapter on general relativity before introducing electromagnetism. This unusual order of presentation works, because he avoids the more conventional chronological approach in favour of a conceptually more logical sequence of ideas. The early emphasis on invariance and conservation laws, convincing in its own right, gives more point to the concluding chapters on unification and the links between cosmology and particle physics.

Although nearly half of the book is addressed to the concepts of particle physics as such, which derive so essentially from the revolutionary consequence of the marriage between relativity and quantum mechanics (namely, that particles can be created and destroyed), that central idea is not brought out as clearly as I think it should and could have been. Quantum mechanics is described as essentially a one-particle affair, and although later there will be a treatment of such detailed topics as the modification of the universal Fermi interaction introduced by Cabibbo, or of the role of the Higgs field in the spontaneous breaking of symmetry in the electroweak theory, or of the renormalizability of gauge theories (!), one reads "in general, source (or matter) particles are conserved, and field (or force) particles are not". That is at best misleading, if not downright false.

It would not be possible to deduce from the text that Adair is Associate Director of the Brookhaven National Laboratory, for many years one of the centres of experimental high-energy and nuclear physics, nor that he himself is a distinguished experimentalist and phenomenologist. Little attempt is made to give more than a cursory description of the experiments from which the conceptual framework of particle physics dervies; indeed, thought experiments are often given more prominence than those in the laboratory. This is a restrained and distanced account, one in which it is difficult to discern any sense of the joy and delight the author must find in his subject; his diffidence and good manners get in the way. For those who already have the motivation and the determination to follow a line of reasoning to its conclusion, Adair is on many topics an excellent guide and mentor, with a good teacher's ability to anticipate the difficulties the student will have.

I suppose, then, that the layman with the "attentive mind" will indeed read this book. If so, he will derive from it what the author had intended, namely an unadorned exposition of the basic concepts of particles and fields and of space and time, as they are understood and used by the professional physicist. That is no mean achievement. But I regret that the account is so sanitized, so lacking in passion and personality, in those humanizing aspects of the pursuit of science which might better have seized the mind and attention of the reader. After all the independent observers in the real world of physics are not matchstick Olivias and Olivers, but real men and women.

J. M. Charap is a Professor in the Department of Physics and Pro-Principal of Queen Mary College, University of London, Mile End Road, London EI 4NS, UK.

\section{New in paperback}

- In Pursuit of the Past: Decoding the Archaeological Record by Lewis R. Binford. Publisher is Thames and Hudson, price is $£ 9.95$, \$17. For review see Nature 303, 449 (1983).

- The New Politics of Science by David Dickson, with a ncw preface. Publisher is University of Chicago Press, price is $\$ 14.95$ (to be published in Britain later this year; originally published by Pantheon). For review see Nature 309, 813 (1984).

- The History of Scurvy and Vitamin $C$ by Kenneth J. Carpenter. Publisher is Cambridge University Press, price is $£ 9.95, \$ 12.95$. For review see Nature 324, 177 (1986). 